\title{
Influence of grease rheology on thrust ball bearings friction torque
}

\author{
Tiago Cousseau, Beatriz M. Graça, Armando V. Campos, Jorge H.O. Seabra
}

\author{
A B S T R A C T
}

The friction torque and the operating temperatures in a thrust ball bearing were measured for seven different types of greases, including three biodegradable greases having low toxicity. These friction torque tests were performed using a modified Four-Ball machine.

Rheological evaluations of the lubricating greases were made using a rheometer. Bleed oils were extracted from the greases and the dynamic viscosities were measured.

In order to compare the performance of the lubricant greases in terms of friction, the grease characteristics were related to experimental results, showing that the interaction between thickener and base oil have strong influences in the bearing friction torque.

\author{
Keywords: \\ Greases \\ Grease rheology \\ Rolling bearing \\ Friction torque
}

\section{Introduction}

The reduction of energy consumption and the increase of the efficiency are, nowadays, an important parameter in the design of machine elements, in particular rolling bearings. Efficiency is also strongly dependant on lubricant formulation and its rheological behaviour.

Rolling bearings are mainly lubricated with grease. Thus, grease rheological behaviour is a key feature to understand lubrication inside a rolling bearing [1,2], to predict film thickness between rolling elements and raceways $[3,4]$, as well as evaluate the internal bearing friction torque.

In this work the rheological behaviour of different types of greases, including biodegradable low toxicity greases, was evaluated using cone-plate geometry in sweep and flow tests. The bleed oil was extracted from the greases and its viscosities were measured at different temperatures.

Thrust ball bearings were tested with all greases and the corresponding internal bearing torque and operating temperature were measured at different speeds. The main objective is to correlate the bearing torque results with the rheological behaviour of the greases.

\section{Methods and materials}

The rolling bearing tests were performed using a modified Four-Ball machine, where the four-ball arrangement was replaced by a rolling bearing assembly, as shown in Fig. 1. The new arrangement was developed to measure the friction torque and the operating temperature in rolling bearings. It is composed by: a shaft adaptor (6), which connects the machine input shaft to the upper race (5); a support (2) and the lower race (3), both clamped to the bearing house (1); a torque cell (11) protected by two plates $(9,13)$, which connect the bearing house (1) to the lower support of the Four-Ball Machine through the pins $(10,12)$. The retainer (7) and the cover (8) avoid the lubricant leakage. In operation, the bearing torque is transmitted to the torque cell through the bearing house.

This assembly has seven thermocouples positioned in strategic locations in order to measure the lubricant and bearing housing temperatures, so that the lubricant viscosity and the heat evacuated through the bearing house can be calculated with reasonable precision. Two of these thermocouples (VI and VII, not shown in Fig. 1) are used to record the temperatures of the air flow surrounding the bearing house and the room temperature.

The rolling bearing assembly is submitted to continuous airforced convection by two fans, having $38 \mathrm{~mm}$ in diameter and running at $2000 \mathrm{rpm}$, evacuating the heat generated during bearing operation for all tests.

The piezoelectric torque cell KISTLER ${ }^{\circledR} 9339$ A selected to measure the friction torque ensures high accuracy measurements even when the friction torque generated in the bearing is very small compared to the measurement range available. The output signal is displayed and registered by the virtual instrument running in a computer.

In the torque tests a 51107 thrust ball bearing was submitted to an axial load of $7000 \mathrm{~N}$, rotational speeds between 350 and $5500 \mathrm{rpm}$ and air-forced convection. The measurements were 


\begin{tabular}{|c|c|c|c|}
\hline \multicolumn{2}{|c|}{ Nomenclature } & $R_{1}$ & geometry constant for rolling frictional moment \\
\hline$C_{0}$ & ellipticity influence parameter $[-]$ & $S_{1}$ & geometry constant for sliding frictional moment \\
\hline$d_{\mathrm{m}}$ & bearing mean diameter $[\mathrm{mm}]$ & & [0.016] \\
\hline$F_{\mathrm{a}}$ & axial load $[\mathrm{N}]$ & $t_{\mathrm{g}}(\delta)$ & loss factor \\
\hline G & material parameter $[-]$ & $U$ & speed parameter $[-]$ \\
\hline$G^{\prime}$ & storage modulus [Pa] & W & load parameter $[-]$ \\
\hline$G^{\prime \prime}$ & loss modulus [Pa] & $\varphi_{\mathrm{bl}}$ & sliding frictional moment weighting factor $[-]$ \\
\hline$G^{*}$ & complex modulus [Pa] & $\varphi_{\text {ish }}$ & inlet shear heating reduction factor $[-]$ \\
\hline$G_{\mathrm{rr} / \mathrm{sl}}$ & $\begin{array}{l}\text { factor that depends on the bearing type, bearing } \\
\text { mean diameter and applied load [-] }\end{array}$ & $\varphi_{\mathrm{rs}}$ & $\begin{array}{l}\text { kinematic replenishment/starvation reduction factor } \\
{[-]}\end{array}$ \\
\hline$h_{0}$ & centre film thickness $[\mu \mathrm{m}]$ & $\dot{\gamma}$ & shear rate $\left[\mathrm{s}^{-1}\right]$ \\
\hline$k$ & consistency index & $\eta_{\text {app }}$ & apparent viscosity [Pa s] \\
\hline$M_{\exp }$ & $\begin{array}{l}\text { bearing friction torque measured experimentally } \\
{[\mathrm{N} \mathrm{mm}]}\end{array}$ & $\begin{array}{l}\eta \\
\mu_{\mathrm{bl}}\end{array}$ & $\begin{array}{l}\text { dynamic viscosity }[\mathrm{Pa} s] \\
\text { coefficient depending on the additive package in the }\end{array}$ \\
\hline$M_{\mathrm{rr}}$ & rolling friction torque $[\mathrm{N} \mathrm{mm}]$ & & lubricant $[-]$ \\
\hline$M_{\mathrm{sl}}$ & sliding friction torque $[\mathrm{N} \mathrm{mm}]$ & $\mu_{\mathrm{EHL}}$ & friction coefficient in full film conditions $[-]$ \\
\hline$M_{\mathrm{t}}$ & total bearing friction torque $[\mathrm{N} \mathrm{mm}]$ & $\mu_{\mathrm{sl}}$ & sliding friction coefficient $[-]$ \\
\hline$v$ & $\begin{array}{l}\text { kinematic viscosity at the operating temperature } \\
{\left[\mathrm{mm}^{2} / \mathrm{s}\right]}\end{array}$ & $\begin{array}{l}\Lambda \\
\tau\end{array}$ & $\begin{array}{l}\text { specific film thickness }[\mu \mathrm{m}] \\
\text { shear stress [Pa] }\end{array}$ \\
\hline$n_{r}$ & flow index & $K_{\mathrm{rs}}$ & starvation constant for grease $\left[6 \times 10^{-8}\right]$ \\
\hline$n$ & rotational speed [rpm] & $K_{\mathrm{z}}$ & bearing type related geometry constant [3.8] \\
\hline
\end{tabular}

performed in three periods of two minutes for each condition with stabilized temperature due to the restrictions imposed by the torque cell. The torque experimental test method is completely described in Cousseau et al. [5].

\subsection{Greases characterisation}

Seven different lubricant greases were tested: $\mathrm{LiM}_{1}$ and $\mathrm{LiM}_{2}$ formulated with mineral base oil and lithium thickener; LiPAO

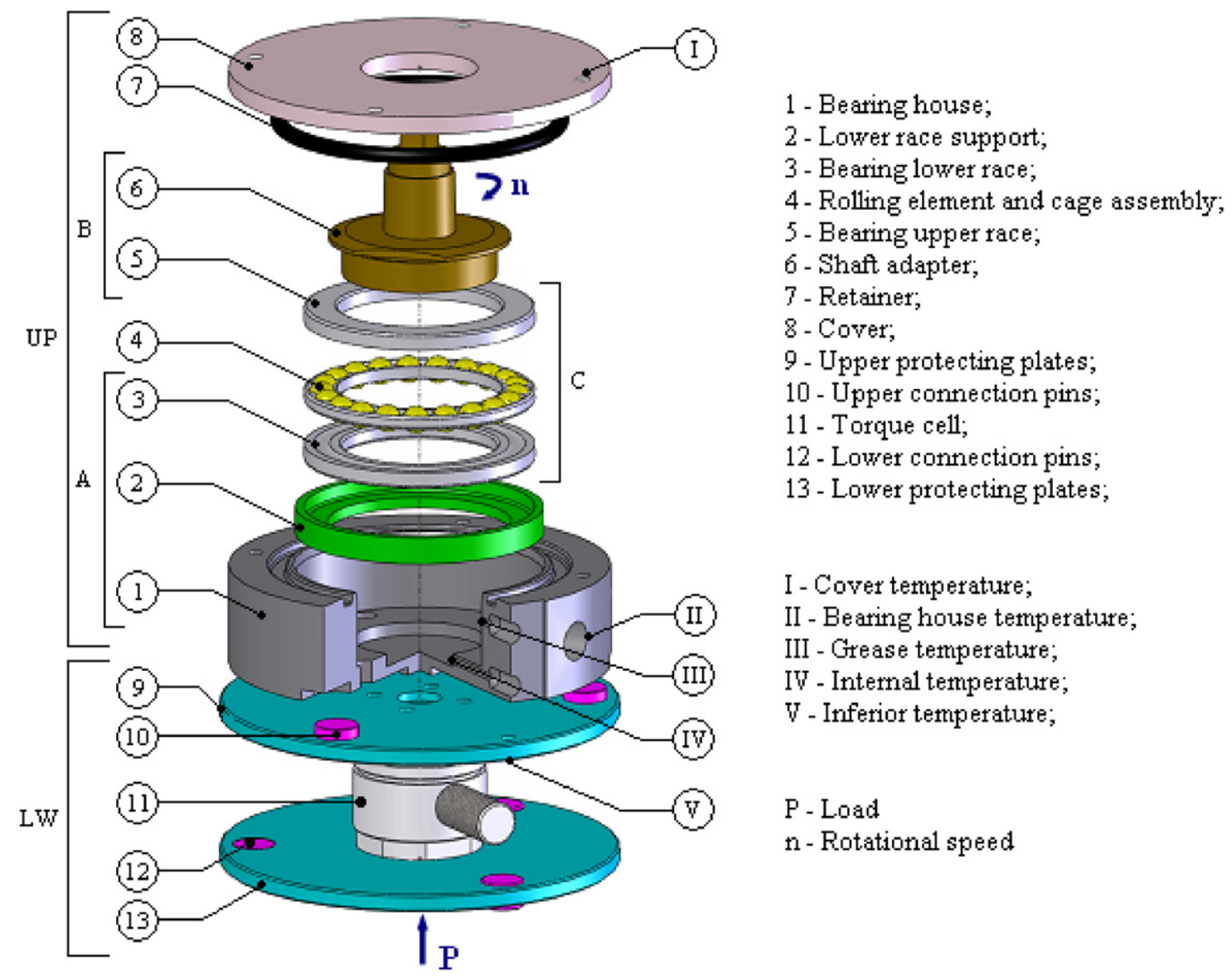

Fig. 1. Bearing assembly: schematic view. 
formulated with polyalfaolefin, lithium thickener and polymeric additivation (PTFE); LiE and LiPuE formulated with ester base oil and both thickened with lithium and calcium, but grease LiPuE also contained polyurea. PPAO and $\mathrm{PE}+\mathrm{V}$ greases, thickened with polypropylene and formulated with polyalphaolefin base oil (PPAO) and a mix of a diester with a vegetal base oil $(\mathrm{PE}+\mathrm{V})$. The physical characteristics of all greases are presented in Table 1.

The polymeric greases are made with a new technology based on non-polar thickener. Three of these greases (LiE, LiPuE and $\mathrm{PE}+\mathrm{V}$ ) passed the tests for biodegradability (OECD 301F and SS155470 class B) and eco-toxicity (OECD 202).

The base oil viscosities shown were measured using an Engler viscometer and the viscosity parameters were calculated.

The grease bleed oil viscosities were measured using a Physica MCR 301 rheometer with a cone-plate geometry CP50-2 $\left(2.02^{\circ}\right.$; $4.997 \mathrm{~mm}$ ) at 40 and $80^{\circ} \mathrm{C}$. The grease bleed oils were obtained according to IP 121 method. In this method, the lubricating grease is pressed against a conical, perforated bottom of a separation cup by application of a specified weight and the device is stored at about $70{ }^{\circ} \mathrm{C}$ in an oven, for $48 \mathrm{~h}$. Depending on the greases tendency to bleed oil, the procedure was repeated as many times as required to obtain enough bleed oil $(2 \mathrm{ml})$ to measure its dynamic viscosity in the rheometer.
The Piezoviscosity $(\alpha)$ at atmospheric pressure was calculated for bleed and base oils according to Gold et al. [6], through equation $\alpha_{0.2}=s v^{t}$, where $s$ and $t$ are variables, which were fitted based on a number of tests with mineral, ester and PAO base oils (see values in the Table 1 ). It was considered that $s$ and $t$ values were valid for base and bleed oils.

The Lubricant Parameter (LP), is defined by the product of the lubricant dynamic viscosity $(\eta)$ by the pressure-viscosity coefficient $(\alpha)$ at atmospheric pressure, and can be directly related to the lubricant film thickness in an EHD contact [7] by the following equation.

$h_{0} \propto(\eta \alpha)^{0.707}$

The grease rheological values were obtained in the MCR 301 rheometer, using again the cone-plate geometry at ambient temperature (around $20^{\circ} \mathrm{C}$ ). Two kinds of tests were carried out: flow tests, in order to measure the apparent viscosity and establish the power-law model to find the $k$ and $n_{r}$ parameters, and sweep tests, with the purpose to evaluate the storage $G^{\prime}$ and loss modulus $G^{\prime \prime}$ to calculate the complex modulus $G^{*}$. The grease rheological parameters are shown in Table 2.

Scanning electron microscopy was performed on a JEOL JSM $35 \mathrm{C} /$ Noran Voyager to better characterize the greases (see Fig. 2).

Table 1

Physical characteristics of the lubricant greases.

\begin{tabular}{|c|c|c|c|c|c|c|c|}
\hline $\begin{array}{l}\text { Designation } \\
\text { Base oil }\end{array}$ & $\begin{array}{l}\operatorname{LiM}_{1} \\
\text { Mineral }\end{array}$ & $\begin{array}{l}\operatorname{LiM}_{2} \\
\text { Mineral }\end{array}$ & $\begin{array}{l}\text { LiPAO } \\
\text { PAO }\end{array}$ & $\begin{array}{l}\text { LiE } \\
\text { Ester }\end{array}$ & $\begin{array}{l}\text { LiPuE } \\
\text { Ester }\end{array}$ & $\begin{array}{l}\text { PPAO } \\
\text { PAO }\end{array}$ & $\begin{array}{l}\boldsymbol{P E}+\boldsymbol{V} \\
\text { Ester + vegetal }\end{array}$ \\
\hline Thickener & $\mathrm{Li}$ & $\mathrm{Li}$ & $\mathrm{Li}$ & $\mathrm{Li} / \mathrm{Ca}$ & Li/Ca-Polyurea & Polypro-pylene & Polypro-pylene \\
\hline Biodegradability (\%) & - & - & - & $>60$ & $>60$ & - & $>60$ \\
\hline Toxicity (\%) & - & - & - & $>45$ & $>45$ & - & $>45$ \\
\hline \multicolumn{8}{|l|}{ Base oil properties } \\
\hline Specific gravity $\left(\mathrm{g} / \mathrm{cm}^{3}\right)$ & 0.903 & 0.900 & 0.900 & 0.952 & 0.952 & 0.828 & 0.915 \\
\hline Base oil viscosity at $40^{\circ} \mathrm{C}\left(\mathrm{mm}^{2} / \mathrm{s}\right)$ & 230 & 110 & 30 & 91.8 & 91.8 & 47 & 32.5 \\
\hline Base oil viscosity at $100{ }^{\circ} \mathrm{C}\left(\mathrm{mm}^{2} / \mathrm{s}\right)$ & 17.5 & 9 & 11.5 & 14.5 & 14.5 & 8 & 6.7 \\
\hline Piezoviscosity at $40{ }^{\circ} \mathrm{C}\left(10^{-9} \mathrm{~Pa}^{-1}\right)$ & 21.09 & 19.04 & 11.72 & 12.21 & 12.21 & 12.32 & 10.60 \\
\hline$\left(\alpha_{0.2 \mathrm{GPa}}=s v^{\mathrm{t}}\right) s$ & 9.904 & 9.904 & 7.382 & 6.605 & 6.605 & 7.382 & 6.605 \\
\hline$t$ & 0.139 & 0.139 & 0.136 & 0.136 & 0.136 & 0.133 & 0.136 \\
\hline LP at $40^{\circ} \mathrm{C} \times 10^{-9}$ (Lubricant Parameter) & 4.38 & 1.88 & 0.32 & 1.07 & 1.07 & 0.48 & 0.31 \\
\hline \multicolumn{8}{|l|}{ Bleed oil properties } \\
\hline Bleed oil viscosity at $40{ }^{\circ} \mathrm{C}\left(\mathrm{mm}^{2} / \mathrm{s}\right)$ & 193.4 & 88.7 & 13.3 & 92.1 & 95.3 & 538.4 & 122.8 \\
\hline Bleed oil viscosity at $100{ }^{\circ} \mathrm{C}\left(\mathrm{mm}^{2} / \mathrm{s}\right)$ & 15.3 & 11.4 & 7.1 & 14.8 & 15.6 & 95.1 & 19.8 \\
\hline Piezoviscosity at $40{ }^{\circ} \mathrm{C}\left(10^{-9} \mathrm{~Pa}^{-1}\right)$ & 20.59 & 18.47 & 10.50 & 12.22 & 12.27 & 17.04 & 12.71 \\
\hline$\alpha_{0.2 \mathrm{GPa}}=\left(s v^{\mathrm{t}}\right) s$ & 9.904 & 9.904 & 7.382 & 6.605 & 6.605 & 7.382 & 6.605 \\
\hline$t$ & 0.139 & 0.139 & 0.136 & 0.136 & 0.136 & 0.133 & 0.136 \\
\hline LP at $40^{\circ} \mathrm{C} \times 10^{-9}$ (Lubricant Parameter) & 3.60 & 1.47 & 0.13 & 1.07 & 1.11 & 7.60 & 1.43 \\
\hline \multicolumn{8}{|l|}{ Grease properties } \\
\hline NLGI Number (DIN 518181) & 2 & 2 & 2 & 2 & 2 & 2 & 2 \\
\hline Dropping point $\left({ }^{\circ} \mathrm{C}\right)$ & 185 & $>190$ & $>185$ & $>180$ & $>181$ & $>140$ & 154 \\
\hline Operating temperature $\left({ }^{\circ} \mathrm{C}\right)$ & -20 to +130 & -30 to +120 & -60 to +120 & -30 to +120 & -30 to +120 & -35 to +120 & -25 to +80 \\
\hline
\end{tabular}

Table 2

Rheological parameters of the greases. in and out of the LVE region.

\begin{tabular}{|c|c|c|c|c|c|c|c|c|c|}
\hline Grease properties & Designation [Units] & $\dot{\gamma}\left(\mathrm{s}^{-1}\right)$ & $\operatorname{LiM}_{1}$ & $\operatorname{LiM}_{2}$ & LiPAO & LiE & LiPuE & PPAO & $P E+V$ \\
\hline Storage modulus & $G^{\prime}[\mathrm{Pa}]$ & 0.001 & 40,600 & 26,900 & 39,300 & 94,400 & 78,800 & 25,800 & 5040 \\
\hline Loss modulus & $G^{\prime \prime}[\mathrm{Pa}]$ & & 5460 & 2040 & 3750 & 13,900 & 11,000 & 4120 & 556 \\
\hline Complex modulus & $G^{*}[\mathrm{~Pa}]$ & & 40,965 & 26,977 & 39,478 & 95,418 & 79,564 & 26,127 & 5070 \\
\hline Loss factor & $\operatorname{tg}(\delta)[/]$ & & 0.134 & 0.076 & 0.095 & 0.147 & 0.140 & 0.160 & 0.110 \\
\hline Storage modulus & $G^{\prime}[\mathrm{Pa}]$ & 10 & 336 & 346 & 389 & 522 & 404 & 488 & 101 \\
\hline Loss modulus & $G^{\prime \prime}[\mathrm{Pa}]$ & & 495 & 469 & 474 & 805 & 647 & 588 & 128 \\
\hline Complex modulus & $G^{*}[\mathrm{~Pa}]$ & & 598 & 582 & 613 & 959 & 763 & 764 & 163 \\
\hline Loss factor & $\operatorname{tg}(\delta)[/]$ & & 1.473 & 1.355 & 1.218 & 1.542 & 1.602 & 1.205 & 1.267 \\
\hline Consistency index & $k\left[\mathrm{~Pa} \mathrm{~s}^{\mathrm{n}}\right]$ & $1-10$ & 455 & 427 & 451 & 752 & 588 & 840 & 165 \\
\hline Flow index & $n_{r}[/]$ & & 0.181 & 0.156 & 0.172 & 0.133 & 0.162 & 0.086 & 0.159 \\
\hline Apparent Viscosity & $\eta=k \cdot \dot{\gamma}^{\left(n_{r}-1\right)}[\mathrm{Pa} \mathrm{s}]$ & 10 & 69.0 & 61.2 & 66.9 & 102.1 & 85.4 & 102.5 & 23.8 \\
\hline
\end{tabular}




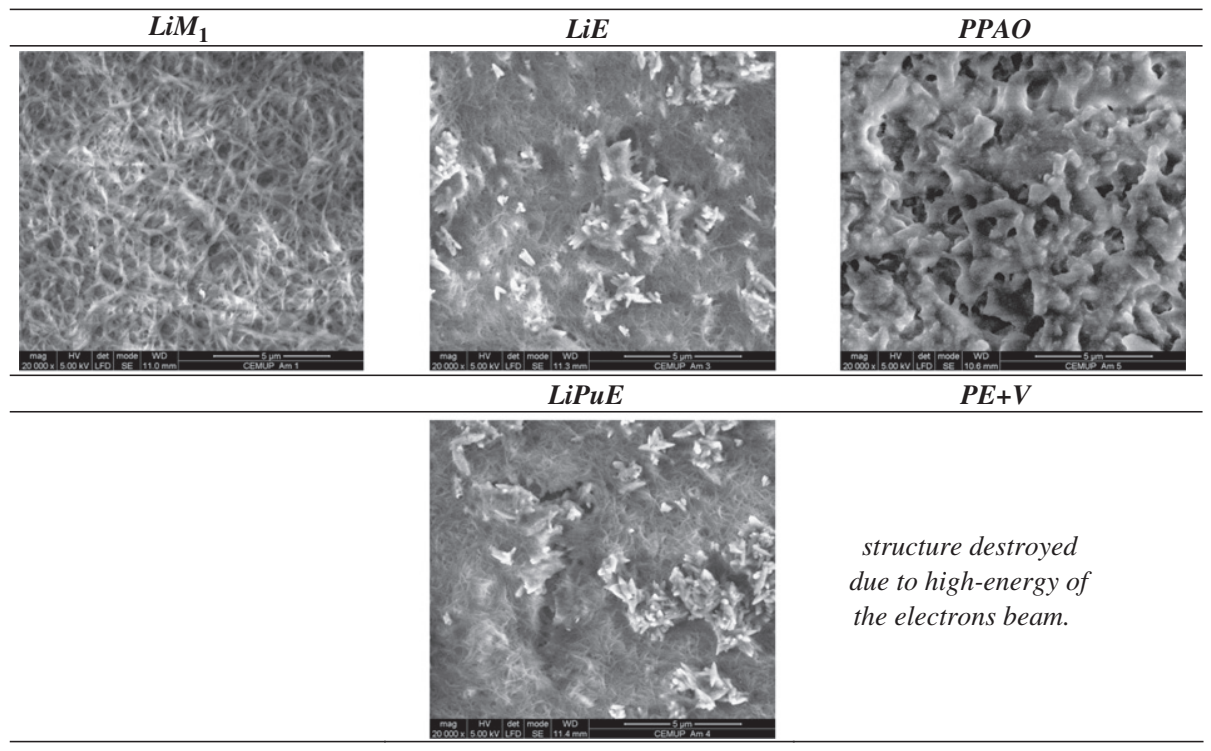

Fig. 2. SEM microphotographs of grease structures $(\times 20,000)$.

The thickener structure images show large differences among the lubricating greases, which are related to the thickener/base oil interaction and the manufacturing process.

$\mathrm{LiM}_{1}$ is a structured system based on entanglement networks, which present long and large lithium fibres. LiE and LiPuE greases contain some large calcium crystals and the lithium fibres are shorter and thinner than $\mathrm{LiM}_{1}$. PPAO and PE $+\mathrm{V}$ greases seem to have a more homogeneous thickener structure, although it is easily damaged by the energy of the incidence electron beam used in high magnification $(20,000 \times)$.

\section{Bearing friction torque model}

The experimental friction torque and bearing temperature values can be used to evaluate the bearing friction torque predicted by the SKF friction torque model. The interested reader is advised to see [8]. The SKF model for a thrust ball bearing is presented in Eqs. (2)-(10) and each parameter is described in "Nomenclature".

$$
\begin{aligned}
& M_{t}=\varphi_{i s h} \times \varphi_{r s} \times \underbrace{\left[G_{r r} \times(v \times n)^{0.6}\right]}_{M_{r r}}+\underbrace{\left[G_{s l} \times\left(\mu_{s l}\right)\right]}_{M_{s l}} \\
& M_{\exp }=M_{t}=M_{r r}^{\prime}+M_{s l} \\
& M_{s l}=M_{t}-M_{r r}^{\prime}=M_{\exp }-M_{r r}^{\prime} \\
& G_{r r}=R_{1} \times d_{m}^{1.83} \times F_{a}^{0.54} \\
& \varphi_{i s h}=\frac{1}{1+1.84 \times 10^{-9} \times\left(n \times d_{m}\right)^{1.28} \times v^{0.64}} \\
& \varphi_{r s}=\frac{1}{\exp \left[K_{r s} \times v \times n \times(d+D) \times \sqrt{\left(K_{z}\right) /(2 \times(D-d))}\right]} \\
& G_{s l}=S_{1} \times d_{m}^{0.05} \times F_{a}^{4 / 3} \\
& \mu_{s l}=\varphi_{b l} \times \mu_{b l}+\left(1-\varphi_{b l}\right) \times \mu_{E H L} \\
& \varphi_{b l}=\frac{1}{\exp \left[2.6 \times 10^{-8} \times(n \times v)^{1.4} \times d_{m}\right]}
\end{aligned}
$$

The application of the SKF bearing friction torque to thrust ball bearings was discussed in previous works $[9,10]$.

\section{Results}

\subsection{Grease rheological parameters}

Amplitude Sweep tests allow to quantify storage $\left(G^{\prime}\right)$ and loss $\left(G^{\prime \prime}\right)$ moduli as a function of the shear rate. The complex modulus $\left(G^{*}\right)$ is determined by the vector sum of the elastic and the viscous components of the grease, as shown in the following equation

$G^{*}=\sqrt{G^{2}+G^{\prime \prime 2}}$

The complex modulus represents the resistance to deformation of the grease. The significant different values of complex moduli shown in Table 2, indicate that the greases have different rheological behaviours. The complex moduli $\left(G^{*}\right)$ measured at a shear rate $(\dot{\gamma})$ of $0.001 \mathrm{~s}^{-1}$, which are inside of the Linear Viscoelastic (LVE) region, are significantly higher than those measured at $10 \mathrm{~s}^{-1}$ (outside of the LVE; see Table 2). In the case of grease Li-E, the values of $G^{*}$ are $G_{0.001}^{*}=95,418$ and $G_{10}^{*}=959 \mathrm{~Pa}$, respectively. Such trend is observed for all greases analysed.

The flow tests were used to measure the apparent viscosity $\left(\eta_{\text {app }}\right)$ as a function of the shear rate $(\dot{\gamma})$. The Ostwald de Waele model, defined by the following equation:

$\eta_{\text {app }}=k \times \dot{\gamma}^{n_{r}-1}$

can be applied to these measurements in order to calculate empirical values for the grease consistency $(k)$ and the flow index $\left(n_{r}\right)$, shown in Table 2 .

The flow index is connected with the shear-thinning characteristics of the grease, e.g., low values on flow index indicates high shear-thinning characteristics and better film-forming ability [11].

The consistency index values for all grease samples are significantly different, going from $165 \mathrm{~Pa} \mathrm{~s}^{n_{r}}$ in the case of grease $\mathrm{PE}+\mathrm{V}$ to $840 \mathrm{~Pa} \mathrm{~s}^{n_{r}}$ in the case of grease PPAO. There is an almost linear relation between the consistency index $(k)$ and the loss modulus $\left(G^{\prime \prime}\right)$, as shown in Fig. 3, where higher loss modulus correspond to higher consistency indices. However, the behaviour of the lithium (Li) thickened greases is different from the behaviour of polypropylene (P) thickened greases.

This linearity is also found between the apparent viscosity $\left(\eta_{\text {app }}\right)$ and the loss modulus $\left(G^{\prime \prime}\right)$, as shown in Fig. 4 , where higher loss moduli correspond to higher apparent viscosities. Once again, the behaviour of the Lithium ( $\mathrm{Li}$ ) thickened greases is different 


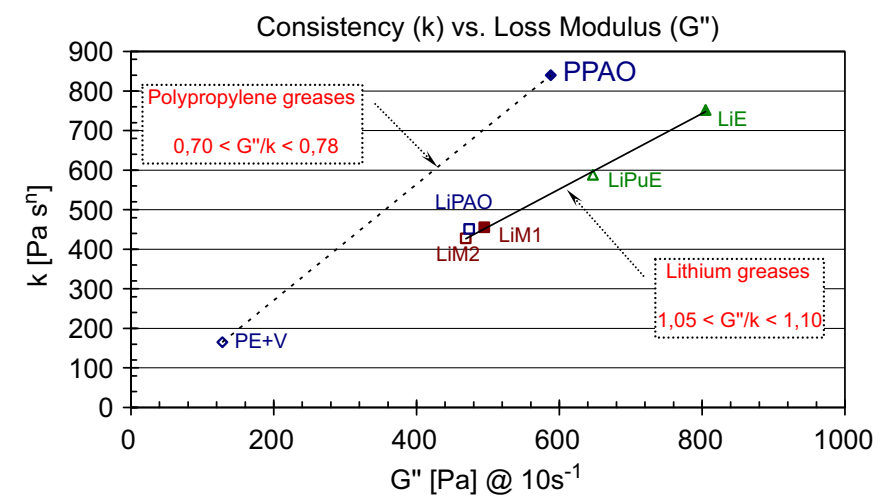

Fig. 3. Consistency index vs. loss modulus for lithium and polypropylene thickened greases out of the LVE region.

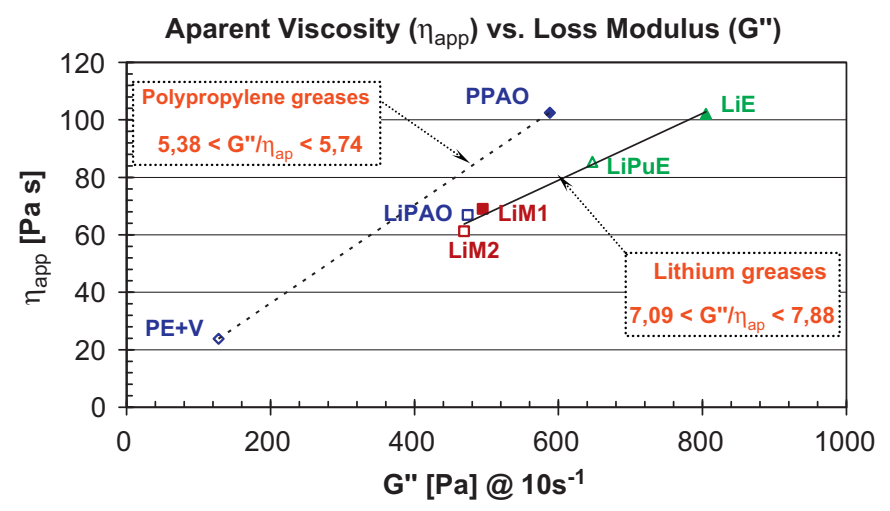

Fig. 4. Apparent viscosity vs. loss modulus for lithium and polypropylene thickened greases out of the LVE (linear visco-elastic) region.

from the behaviour of polypropylene $(\mathrm{P})$ thickened greases, as shown by the relations of $G^{\prime \prime} / k$ and $\eta_{\text {app }} / G^{\prime \prime}$ :

- Lithium greases: $1.05 s^{-n_{r}}<\left(G^{\prime \prime} / k\right)<1.10 s^{-n_{r}}$ and $7.09 s^{-1}<\left(G^{\prime \prime} /\right.$ $\left.\eta_{\text {app }}\right)<7.88 \mathrm{~s}^{-1}$;

- Polypropylene greases: $0.70 s^{-n_{r}}<\left(G^{\prime \prime} / k\right)<0.78 s^{-n_{r}}$ and $5.38 s^{-1}<$ $\left(G^{\prime \prime} / \eta_{\text {app }}\right)<5.74 s^{-1}$.

The thickener structure dissimilarities between lithium and polypropylene greases seem to be one of the major influences for this behaviour. Lithium is a metal soap with a polar structure, where their molecules are arranged into fibrils, building up a three-dimensional network held by Van Der Waals, electrostatic and hydrogen bonds. Polypropylene is a non-polar organic thickener with high molecular weight, forming a network of entangled molecules with crystalline elements clamped together only by Van der Waals forces. These molecular structure differences together with distinct solubility's in the fluid phase, contributes for specific bonding energies between their molecules influencing their behaviour when sheared.

Table 2 presents the dynamic viscosities of the grease base oils as well as the viscosities of the bleed oils, which are compared in Fig. 5. In the case of lithium (Li) thickened greases the viscosity of the bleed oil is always lower than the viscosity of the base oil, and such difference is very significant in the case of greases LiM1, LiM2 and LiPAO formulated with mineral and polyalphaolefin base oils, while in the case of greases formulated with ester oils (LiE and LiPuE) such difference is insignificant. In the case of the polypropylene $(\mathrm{P})$ thickened greases the opposite trend is observed, and the viscosity of the bleed oil is always higher than

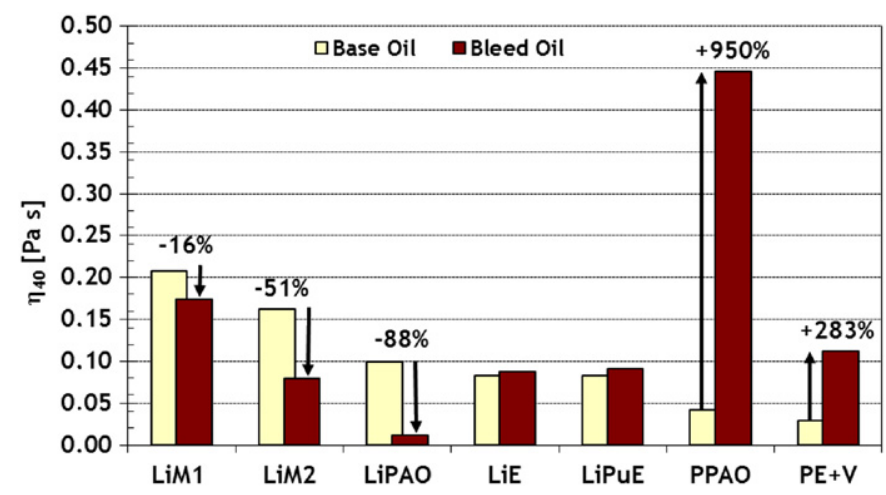

Fig. 5. Dynamic viscosity at $40{ }^{\circ} \mathrm{C}$ of the grease base oils and bleed oils.

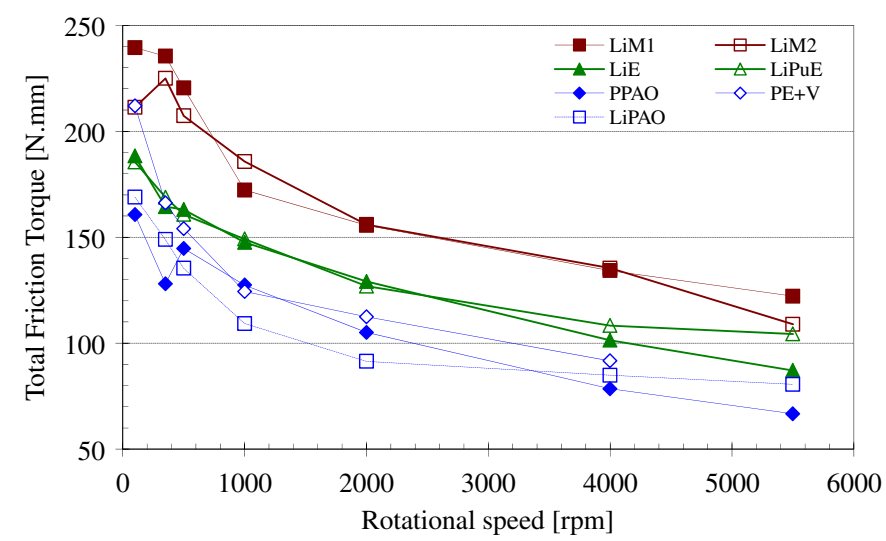

Fig. 6. Torque measured vs. bearing speed.

the viscosity of the base oil. Once again, two different behaviours are observed, that is,

- Lithium Greases: $\eta_{\text {bleed_oil }}<\eta_{\text {base_oil; }}$

- Polypropylene Greases: $\eta_{\text {bleed_oil }}>>\eta_{\text {base_oil. }}$

Since the grease bleed oils have been obtained through a static method, where the grease is pressed against a perforated conic surface, some grease constituents may went through the mesh openings together with the bleed oil. The reason for the large difference between the base oil viscosity and the bleed oil viscosity in the polypropylene grease could be related with the presence of the elastomer (1-5\%) that bleeds out together with the oil-leading to a much higher bleed oil viscosity.

\subsection{Experimental friction torque and operating temperatures}

The bearing friction torque measured is plotted against the rotational speed in Fig. 6, for all greases tested. The measurements show that the bearing torque reached the highest values with the mineral greases $\left(\mathrm{LiM}_{1}\right.$ and $\mathrm{LiM}_{2}$ ) and the lowest ones with the polymeric greases (PPAO, PE $+\mathrm{V}$ and LiPAO), while the torque values corresponding to the ester-based greases ( $\mathrm{LiE}$ and $\mathrm{LiPuE}$ ) are between mineral and polymeric greases. The bearing friction torque decreases when the rolling bearing speed increases.

The highest operating temperatures measured, corresponding to thermocouple III (see Fig. 1), are plotted against the rotational speed in Fig. 7. The highest temperature values correspond to the mineral greases $\left(\mathrm{LiM}_{2}\right.$ and $\left.\mathrm{LiM}_{1}\right)$, the polymeric greases (PPAO, $\mathrm{PE}+\mathrm{V}$ and LiPAO) showed the lowest ones, while the ester-based 


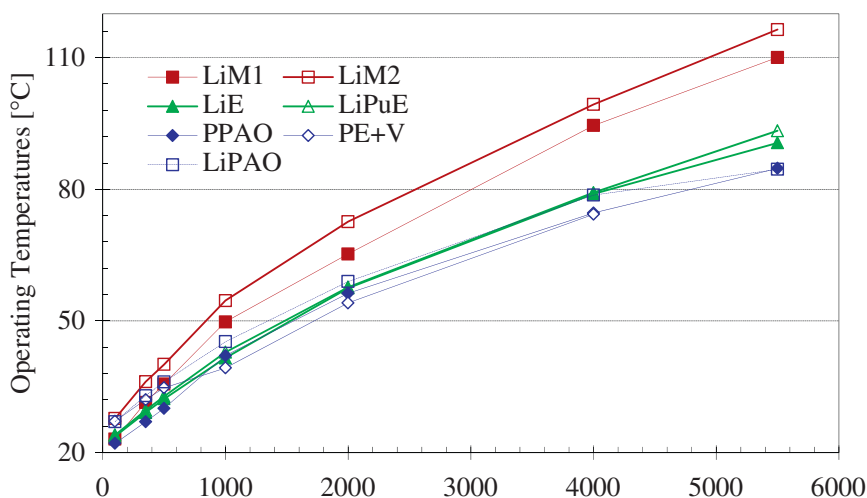

Fig. 7. Operating temperature vs. bearing speed.

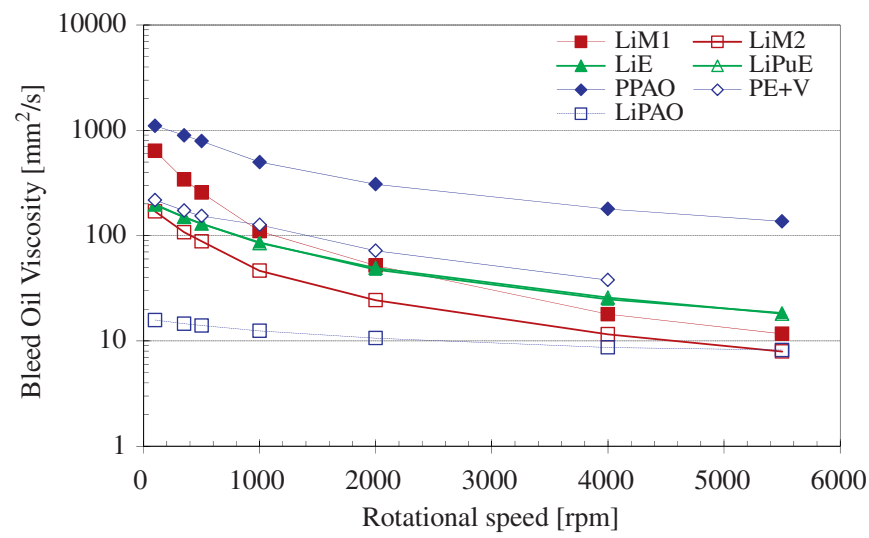

Fig. 8. Bleed oil viscosity vs. bearing speed.

greases ( $\mathrm{LiE}$ and $\mathrm{LiPuE}$ ) presented temperatures between the other two, which is in close agreement with the friction torque measurements.

At $2000 \mathrm{rpm}$, the frictional torque and the operating temperature of the grease $\mathrm{LiM}_{2}$ were significantly higher than the polymeric grease PPAO, respectively, $42.9 \%$ and $22.5 \%$. At $5500 \mathrm{rpm}$, the operating temperature for the grease $\mathrm{PE}+\mathrm{V}$ was out of the range $\left(101^{\circ} \mathrm{C}\right.$ ) of specified limits (see Table 1$)$. Therefore, the measured and calculated values were not taken into account for that condition.

\subsection{Bleed oil viscosity}

Fig. 8 shows the calculated kinematic viscosities (ASTM D341) of the grease bleed oils at the bearing operating temperatures, for each rotational speed. In general, the viscosities of the grease bleed oils decreased when the bearing operating speed increases, because of the corresponding temperature increase.

At $2000 \mathrm{rpm}$ the bleed oils of the polypropylene greases (PPAO and $\mathrm{PE}+\mathrm{V}$ ) had the highest kinematic viscosities (respectively $308 \mathrm{cSt}$ and $72 \mathrm{cSt}$ ), followed by the bleed oils of the ester-based greases LiE, LiPuE and the mineral grease LiM1 (around 50cSt). The bleed oil of the mineral grease LiM2 (24cSt) had lower viscosity than the bleed oil LiM1. Finally, the bleed oil of grease LiPAO had the lowest viscosity $(9 \mathrm{cSt})$, which remains almost constant whatever the operating speed, probably as a consequence of the polymer additive used in the formulation of this particular grease.

Thus, the bleed oil viscosity inside the thrust ball bearing depends on two main factors: (i) the type of grease thickener (lithium or polypropylene) and on the interaction between thickener and base oil (e.g. greases LiM2 and LiE), as shown in Fig. 5, and (ii) the operating temperature corresponding to each speed and grease (see Fig. 7).

\subsection{Rolling and sliding friction torque}

The SKF friction torque model was correlated with the experimental torque values, taking into consideration the bearings dimensions and the operating conditions (load and speed), allowing the determination of the rolling and sliding bearing torques, respectively $M_{\mathrm{rr}}^{\prime}$ and $M_{\mathrm{sl}}$, see Eqs. (2)-(10).

The rolling torque, $M_{\mathrm{rr}}^{\prime}$, was predicted using the SKF model, and was plotted against bearing speed in Fig. 9.

Fig. 9 shows that the rolling torque $\left(M_{\mathrm{rr}}^{\prime}\right)$ is mainly dependant on the viscosity of the bleed oil at the operating temperature, and thus, higher bleed oil viscosities generate higher rolling torques, at constant speed. However, the rolling torque is also dependant on the kinematic replenishment factor $\left(\varphi_{\mathrm{rs}}\right)$, which becomes important for high viscosities at high speed, as in the case of PPAO grease (see Fig. 8). In the case of grease LiPAO the rolling torque increased when the operating speed increased, because the viscosity of the corresponding bleed oil is almost constant, depending very little on temperature (see Fig. 8).

The sliding torque $\left(M_{\mathrm{s} \ell}\right)$ was calculated using equation 4 , that is, $M_{\mathrm{s} \ell}=M_{\mathrm{exp}}-M_{\mathrm{rr}}^{\prime}$, and is presented in Fig. 10. It is interesting to notice that the lithium thickened greases (LiM1, LiM2 and LiPAO) generated the highest sliding torques and simultaneously the corresponding bleed oils had the highest decrease in viscosity when compared with their base oils (see Fig. 5), while the Polypropylene thickened greases (PPAO and PE $+\mathrm{V}$ ) show exactly the opposite trend, that is, lowest sliding torques and a high increase in viscosity when compared with their base oils. The sliding torque of greases LiE and LiPuE are in between those just mentioned, which had bleed and base oils with similar viscosities.

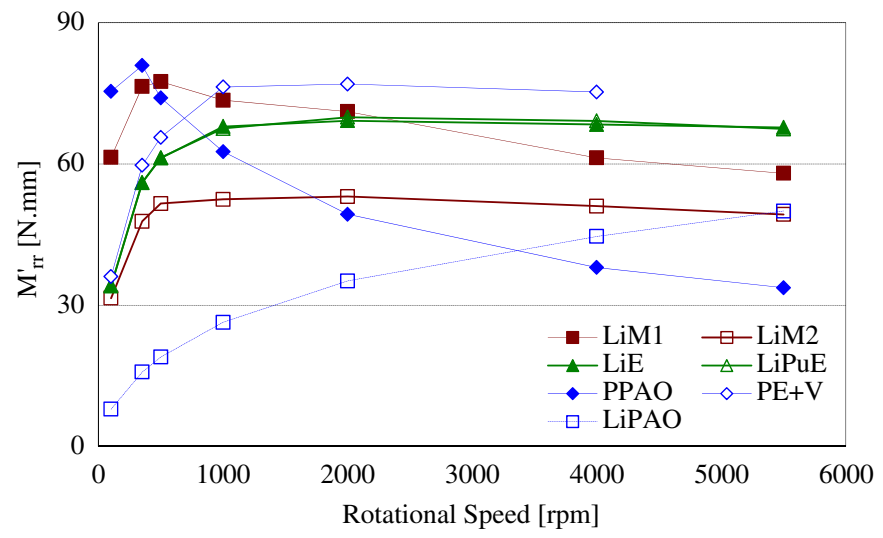

Fig. 9. Rolling friction torque vs. bearing speed.

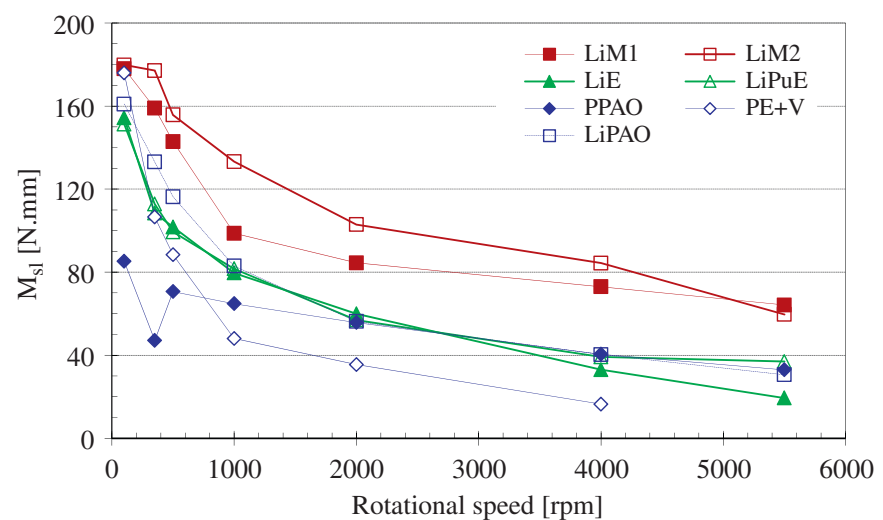

Fig. 10. Sliding friction torque vs. bearing speed. 
Once more these trends are a clear sign of the influence of the grease thickener and of the interaction between thickener and base oil on the bearing sliding torque.

\section{Discussion}

Despite of the highly complex behaviour of lubricant greases, a qualitative and quantitative analysis of the results suggests that the bleed oil properties and the interaction between thickener and base oil are the predominant factors in the tribological behaviour of a grease lubricated thrust ball bearing.

In Fig. 11 the bearing rolling torque $\left(M_{\mathrm{rr}}^{\prime}\right)$ was plotted against the operating bleed oil viscosity for three different speeds, 350, 1000 and $4000 \mathrm{rpm}$. According to Eq. (1), rolling torque increases when the operating viscosity and/or the operating speed increases and Fig. 11 clearly indicates that, at constant speed, higher bleed oil viscosities generate higher rolling torques. However, when speed increases the operating temperature also increases and the bleed oil viscosity decreases. If this decrease in viscosity is small (see Fig. 8) the rolling torque increases (e.g. grease LiPAO), if the viscosity decrease is significant the rolling torque decreases (e.g. grease LiM1) or remains almost constant (e.g. grease LiM2).

Another important aspect is the influence of the grease thickener: in the case of Lithium greases the bleed oil has lower viscosity than the base oil, while the opposite occurs in the case of the Polypropylene greases. This different behaviour is clear comparing the variation of the rolling friction with the bleed oil viscosity for Lithium and Polypropylene greases, shown in Fig. 11.

In the case of grease PPAO the influence of the contact replenishment is also very clear. At high speed, the high viscosity bleed oil of this grease generates poor contact replenishment and the rolling torque decreases significantly.

The bleed oil viscosity was used to calculate the theoretical centre film thickness in the ball-race contact of the thrust ball bearing, for each operating speed and grease, as shown in Fig. 12. The centre film thickness was determined using the Hamrock and Dowson [7] equation for elliptical contacts, i.e.

$H_{0}=1.345 \times R_{x} \times U^{0.67} \times G^{0.530} \times W^{-0.067} \times C_{0}$

At $2000 \mathrm{rpm}$ the film thickness calculated for the different greases were: $0.74 \mu \mathrm{m}$ for PPAO, $0.28 \mu \mathrm{m}$ for $\mathrm{LiM}_{1}$ and $\mathrm{PE}+\mathrm{V}$, $0.22 \mu \mathrm{m}$ for LiE and LiPuE, $0.17 \mu \mathrm{m}$ for $\mathrm{LiM}_{2}$ and $0.08 \mu \mathrm{m}$ for LiPAO. Fig. 12 also shows the corresponding specific lubricant film thickness $(\Lambda)$ values.

Fig. 12 shows that, for an operating speed of $2000 \mathrm{rpm}$, grease PPAO had a $\Lambda$ equal to 4.1, greases LiM1, LiE, LiPuE and PE $+\mathrm{V}$ had $\Lambda$ values around $1.5(1.2<\Lambda<1.6)$, grease LiM2 had a $\Lambda$ equal to

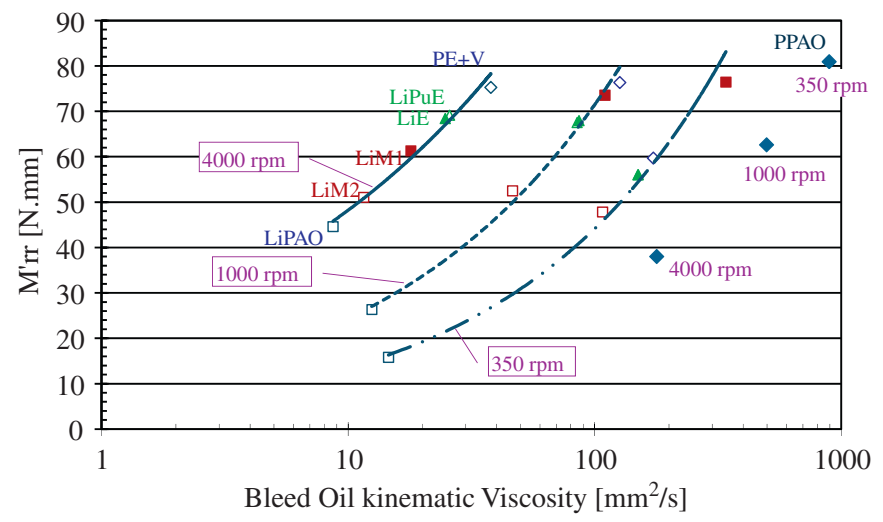

Fig. 11. Bearing rolling torque $\left(M_{\mathrm{rr}}^{\prime}\right)$ vs. bleed oil viscosity $(v)$ at the operating temperature.

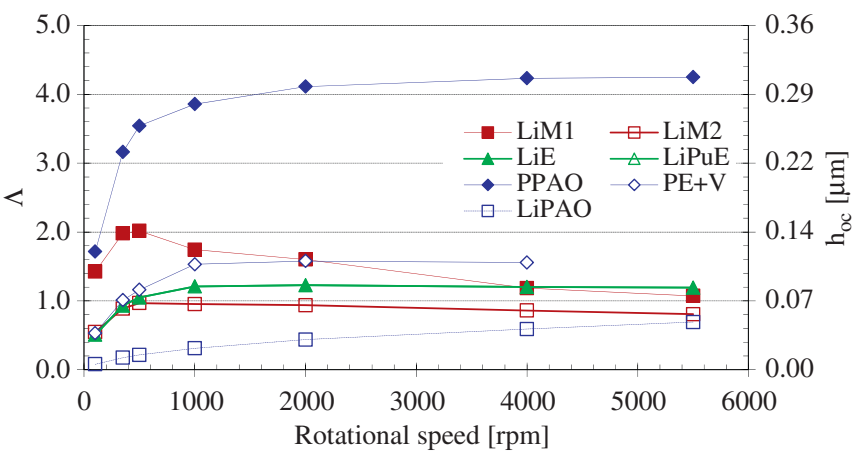

Fig. 12. Specific film thickness $(\Lambda)$ and film thickness $\left(h_{\mathrm{oc}}\right)$ vs. bearing speed.

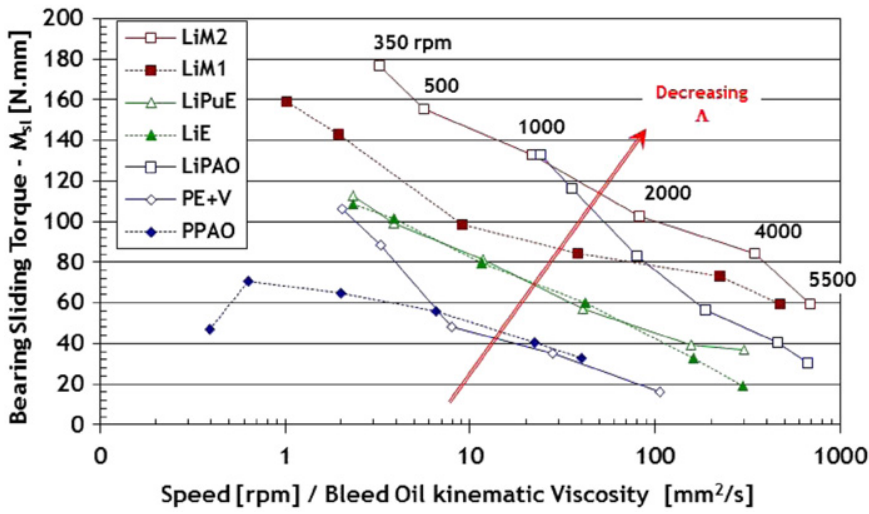

Fig. 13. Bearing sliding torque $\left(M_{\mathrm{s} \ell}\right)$ vs. speed/bleed oil viscosity $(n / v)$, at the operating temperature.

0.9 and grease LiPAO had a $\Lambda$ equal to 0.4 . The comparison between Figs. 8 and 12 indicates that the operating specific film thickness is strongly dependant on the viscosity of the bleed oil at the operating temperature.

Since the thrust ball bearing tests were not performed at constant temperature, when the speed increased, the temperature increased and the bleed oil viscosity decreased. For this reason, in Fig. 13 the bearing sliding torque $\left(M_{\mathrm{s} \ell}\right)$ was plotted against the ratio $n / v$ (speed/bleed oil viscosity) and not the product $n v$ as usual.

Fig. 13 indicates that when the ratio $n / v$ increased the bearing sliding torque decreased, whatever the grease considered. The relative position of the different greases depends on two main aspects: specific lubricant film thickness and nature of the bleed oil. In fact, for the same operating conditions, the bearing sliding torque increases when the specific film thickness decreases, as shown in Fig. 13. However, the sliding torque also depends on the nature of the base/bleed oil since mineral oils generate higher friction than PAO-based and ester-based oils [11], for the same operating conditions and viscosities.

Such influences are also included in the bearing sliding torque predicted by the SKF bearing friction model, as postulated by Eqs. (8)-(10), where the weighting factor $\varphi_{\mathrm{b} \ell}$ takes into account the specific lubricant film thickness $(\Lambda)$ and the friction coefficients in boundary and full film lubrication, respectively $\mu_{\mathrm{b} \ell}$ and $\mu_{\mathrm{EHL}}$, depend on the operating conditions but also on the nature of the lubricant (Mineral, PAO or Ester).

\section{Conclusion}

1. Grease rheology is strongly dependant on the thickener type. A linear relation was observed between the loss modulus $G^{\prime \prime}$ and 
consistency $k$ of the grease, which is $1.05-1.10$ for Lithium thickened greases and $0.70-0.78$ for polypropylene thickened greases.

2. The viscosity of the bleed oil is higher than the viscosity of the base oil in the case of polypropylene thickened greases and the opposite was observed in the case of lithium thickened greases.

3. The bearing rolling torque $\left(M_{\mathrm{rr}}^{\prime}\right)$ is mainly dependant on the viscosity of the bleed oil at the operating temperature and on the replenishment of the contact $\left(\varphi_{\mathrm{rs}}\right)$.

4. The bearing sliding torque $\left(M_{\mathrm{sl}}\right)$ is mainly dependant on the specific film thickness of the ball-race contact and on the nature of the bleed oil (Mineral, PAO or Ester).

\section{Acknowledgements}

The authors wish to thank the Fundação para a Ciência e Tecnologia from the Portuguese Administration for the financial support given to this work through the project "Low friction, biodegradable and low toxicity greases for rolling bearings", through research contract PTDC/EME.PME/72641/2006. The authors would like to thank Dr. Harald Bock from ROWE Mineralölwerk Gmbh, in Bubenheim, Germany, for supplying the ester based greases LiE and LiPuE, and Dr. Michael Kruse from AXEL Christiemsson $A B$, Sweden, for supplying the polymer thickened greases PPAO and PE $+\mathrm{V}$.

\section{References}

[1] Couronné I, Vergne P, Mazuyer D, Truong-Dinh N, Girodin D. Nature and properties of the lubricating phase in grease lubricated contact. Tribology Transactions 1 2003;46:37-43, doi:10.1080/10402000308982597.

[2] Cann PM. Grease lubrication of rolling element bearings-role of the grease thickener. Lubrication Science 2007;19:183-96, doi:10.1002/ls.39.

[3] Lubrecht T, Mazuyer D. and Cann P., Starved elastohydrodynamic lubrication theory: application to emulsions and greases, surfaces, interfaces, films. In: Applied physics, Series IV. Paris, t. 2: C. R. Acad. Sci., 717-728, 2001.

[4] Cann PME, Damiens B, Lubrecht AA. The transition between fully flooded and starved regimes in EHL. Tribology International 2004;37:859-64, doi:10.1016/ j.triboint.2004.05.005.

[5] Cousseau T, Graça B, Campos A, Seabra J. Experimental measuring procedure for the friction torque in rolling bearings. Lubrication Science 2010;22:133-47, doi:10.1002/ls.115.

[6] Gold P, Schmidt A, Dicke H, Loos J, Assmann C. Viscosity-pressure-temperature behaviour of mineral and synthetic oils. Journal of Synthetic Lubrication 2001;18(1):51-79.

[7] Hamrock BJ, Dowson D. Ball Bearing Lubrication, The Elastohydrodynamics of Elliptical Contacts. John Willey and Sons; 1981.

[8] SKF General Catalogue 6000EN. November 2005

[9] Cousseau T, Graça B, Campos A, Seabra J. Influence of grease formulation on thrust bearings power loss. Proceedings of the IMechE 2010;224 Part J:935-46, doi:10.1243/13506501JET724.

[10] Cousseau T, Graça B, Campos A, Seabra J. Friction torque in grease lubricated thrust ball bearings. Tribology International 2011;44:523-31, doi:10.1016/ j.triboint.2010.06.013.

[11] Bair S. High pressure rheology for quantitative elastohydrodynamics. Tribology and Interface Engineering Series 2007;54:177-8. 